\title{
Modeling of facade elements with switchable U-value
}

\author{
Thibault Pflug a,c,*, Nikolaus Nestle ${ }^{\mathrm{b}}$, Tilmann E. Kuhn ${ }^{\mathrm{a}}$, Monica Siroux ${ }^{\mathrm{c}}$, Christoph Maurer $^{\mathrm{a}}$ \\ a Fraunhofer Institute for Solar Energy Systems ISE, Heidenhofstrasse 2, 79110 Freiburg, Germany \\ ${ }^{\mathrm{b}}$ BASF SE Advanced Materials and Systems Research, 67056 Ludwigshafen, Germany \\ 'ICube UMR7357, Université de Strasbourg, INSA Strasbourg, 24 boulevard de la Victoire, 67084, Strasbourg Cedex, France
}

\section{A R T I C L E I N F O}

\section{Article history:}

Received 19 January 2017

Revised 15 November 2017

Accepted 20 December 2017

Available online 10 January 2018

\begin{abstract}
A B S T R A C T
In this contribution, a new model of switchable insulation element is introduced. This element essentially consists of a double glazing unit with a translucent insulating panel mounted inside. Switching of the Uvalue is achieved by control of an internal convective flow around the insulation panel. The element can be in an insulating state with a low U-value, or in a conducting state with a high U-value. First the new model of the element, based on numerous thermal, hydraulic and optical assumptions, is introduced. The airflow rate is calculated by balancing the pressure drops and the buoyancy driving force. The model is validated against U-value measurements, showing a reasonable accuracy. Finally, the model is used for a parametric analysis, where the influence of different thermophysical properties on the U-value and gvalue of the element in insulating and conducting state is investigated.
\end{abstract}

(c) 2017 Elsevier B.V. All rights reserved.

\section{Introduction}

\subsection{General introduction}

In the European continental climate as well as in many other climates, one of the most obvious and cost-effective way to decrease a building's energy demand is to insulate the building's envelope. However, the increase of the thermal insulation of the building skin, leading to very low and quasi constant U-values, can also avoid benefitial heat fluxes through the building skin, e.g. in cold summer nights. Additional insulation can therefore slow down the nocturnal cooling process in summer [1].

To reduce the overheating risk in buildings without mechanical cooling systems as well as the cooling loads in buildings with HVAC system, state of the art solutions include for example the use of shading devices such as e.g. external blinds [2] or glazing solutions with reduced g-values [3]. Ventilation and free cooling are also a traditional way to reduce the cooling loads, but the external air led into the building brings the issues of filtering, pollution and allergies and can lead to substantial additional consumption of electricity to drive the ventilation fans. Opening windows can be effective but comes with security and noise problems. Also, reducing the internal heat gains can be a simple solution if possible.

\footnotetext{
* Corresponding author at: Fraunhofer Institute for Solar Energy Systems ISE, Heidenhofstrasse 2, 79110 Freiburg, Germany

E-mail address: thibault.pflug@ise.fraunhofer.de (T. Pflug).
}

\subsection{Switchable insulation}

Another additive solution is the use of facade elements with switchable U-value, or switchable insulations. Switchable insulations are facade systems whose thermal resistance can be switched to a lower value whenever profitable to decrease the building's heating and cooling demand. For example for an european continental climate as defined in [4], during the cooling period, the facade can be switched to a higher U-value whenever the external environmental temperature is lower than the indoor one in order to cool down the building, in particular during night time.

Facade elements with switchable thermal resistance are not a new idea, existing concepts being for example the simple physical removal of the thermal insulation [5], the filling or emptying of a cavity with insulating foam spheres [6], the rear-ventilation of an insulation system [7], the collapsing [8] or removing [9-11] of series of air cavities, the release and absorption of hydrogen gas by a metal hydride within a panel [12], the controlled convection in wall structures [13] or the change of internal pressure in nanomaterials [14]. While these systems can be switched actively, for example by the use of an electrical input, another category of systems would be passive switchable systems, using for example bimetals to switch the U-value depending on the environment. The advantage is that these systems are autonomous, but the disadvantage is that passive systems can not always switch when it would be best for the building's energy balance. 


\section{Nomenclature}

d $\quad[\mathrm{m}] \quad$ the thickness of the gas cavity.

$D_{h} \quad$ [m] the hydraulic diameter of the duct.

$g=9.81 \quad\left[\mathrm{~m} \mathrm{~s}^{-2}\right] \quad$ the gravity constant.

g [-] the g-value of the element.

$h \quad[\mathrm{~m}] \quad$ the height along the vertical axis.

$H \quad[\mathrm{~m}] \quad$ the height of the glazed surface.

$h_{c v} \quad\left[\mathrm{~W} \mathrm{~m}^{-2} \mathrm{~K}^{-1}\right]$ convective heat transfer coefficient.

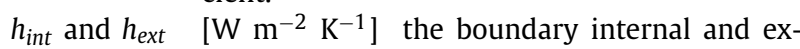
ternal heat transfer coefficients.

$h_{\text {rad }} \quad\left[\mathrm{W} \mathrm{m}^{-2} \mathrm{~K}^{-1}\right]$ the radiative heat transfer coefficient.

I $\quad\left[\mathrm{W} \mathrm{m}^{-2}\right]$ the total irradiance arriving at the element's outer surface.

$L \quad[\mathrm{~m}] \quad$ the length of the duct.

$\mathrm{Nu} \quad[-]$ the mean Nusselt number in the duct.

Pr [-] the mean Prandtl number in the duct.

$q_{\text {int }} \quad\left[\mathrm{W} \mathrm{m}^{-2}\right.$ ] the total heat flux from the interior

glass pane towards the room.

Re [-] the mean Reynolds number in the duct.

$T \quad[\mathrm{~K}] \quad$ the air or surface temperatures.

$U \quad\left[\mathrm{~W} \mathrm{~m}^{-2} \mathrm{~K}^{-1}\right]$ the center of glazing $\mathrm{U}$-value.

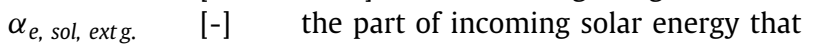
is absorbed in the external glass layer.

$\alpha_{h h} \quad$ [-] the hemispherical-hemispherical absorptance.

$\Delta P_{\text {driving }} \quad[\mathrm{Pa}] \quad$ the driving pressure difference.

$\Delta P_{\text {system }} \quad$ [Pa] the sum of the pressure drops in the system.

$\Delta T \quad[\mathrm{~K}] \quad$ temperature difference at the boundary of the facade element.

$\epsilon \quad[-] \quad$ the surface longwave emissivity.

$\lambda_{\text {insu. }} \quad\left[\mathrm{W} \mathrm{m}^{-1} \mathrm{~K}^{-1}\right.$ ] the thermal conductivity of the insulation layer.

$\rho \quad\left[\mathrm{kg} \mathrm{m}^{-3}\right]$ density of the fluid.

$\rho_{h h} \quad[-]$ the hemispherical-hemispherical reflectance.

$\sigma=5.67 * 10^{-8} \quad\left[\mathrm{~W} \mathrm{~m}^{-2} \mathrm{~K}^{-4}\right]$ the Stefan-Boltzmann constant.

$\tau_{h h} \quad[-]$ the hemispherical-hemispherical transmittance.

\subsection{Closed translucent switchable insulation}

In [15], a new closed translucent element with switchable insulation is presented. The patented concept [16] is based on controlled convection inside a closed module containing one or several insulating panes. Another concept with controlled natural or forced convection within a wall was also analyzed theoretically by Hagentoft [13].

In the concept presented here, the new facade element can be in two states (Fig. 1):

- In the insulating state (left) the insulation panel is at the top. In this state, no large-scale convection around the panel is possible and the element behaves like a system with three insulating vertical layers: two thin air layers and an insulation panel. In this state, the convective exchange at the bottom is negligible, as shown during experimental analysis in [15].

- In the conducting state (right), the insulation panel is moved in a vertical middle position, with air gaps at the top and the bottom. The difference of temperature between the interior and
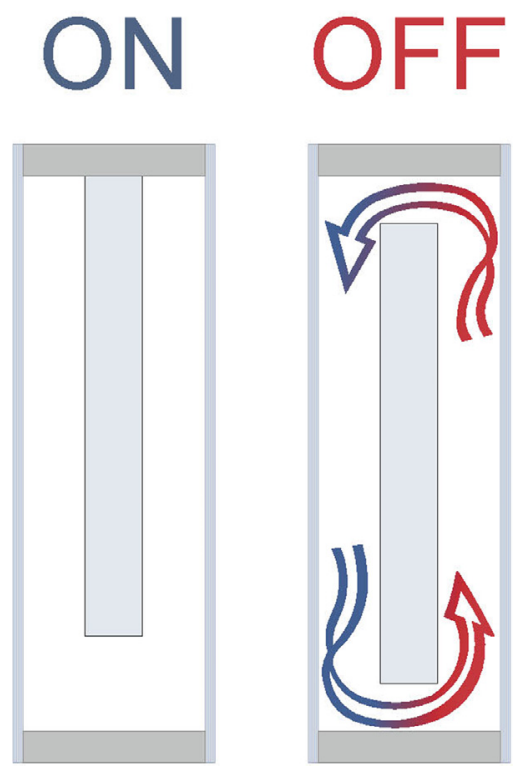

Fig. 1. Translucent switchable facade element in the insulating state (left) and in the conducting state (right).The dimensions are not true to scale. Source: Fischer Architekten.

the exterior induces large-scale spontaneous convection around the insulation panel due to the difference of density between the outer and inner air columns.

The translucent insulation material used for the test models was Basotect ${ }^{\circledR}[17]$, which is an insulation and sound absorption material developed by BASF. It is a low-density, open pore melamine foam and has a thermal conductivity at $20^{\circ} \mathrm{C}$ of $0.035 \mathrm{~W}$ $\mathrm{m}^{-1} \mathrm{~K}^{-1}[17]$.

An extensive experimental study has been conducted in [15], showing for example that the U-value of a prototype with $3 \mathrm{~cm}$ thick vertical air gaps and a $3 \mathrm{~cm}$ thick insulation panel could be switched from about $0.9 \mathrm{~W} \mathrm{~m}^{-2} \mathrm{~K}^{-1}$ in the insulating state to $1.7 \mathrm{~W}$ $\mathrm{m}^{-2} \mathrm{~K}^{-1}$ in the conducting state. The influence of different geometrical parameters, of the use of two vertical insulation panels instead of one, and of the use of $\mathrm{CO}_{2}$ instead of air has also been studied. Using two vertical insulation panels with an air layer in between allows to have the same insulation potential in the insulating state as an equivalent one-panel construction, while having a higher translucency to decrease the building's artificial lighting consumption. Also, in insulating state, the radiative and convective heat transfer between the inner and outer air column at the bottom of the element is prevented even better.

In [15], a case study on building level using TRNSYS was also presented, highlighting the potential of the concept. Compared to the reference office on passive house level with the climate of Ludwigshafen (Germany), a variant using the first measured prototype has been simulated in the upper part of the facade, showing a reduction due to the switching of the U-value of about $10 \%$ of the cooling demand. Also, large improvements in the summer operative temperature were shown in a second simulation without cooling. An optimized element with a higher U-value in the conducting state of $3 \mathrm{~W} \mathrm{~m} \mathrm{~m}^{-2} \mathrm{~K}^{-1}$ could lead to a reduction of the cooling demand by about a third. However, later results presented in [18] have indicated that due to the very low visible transmittance of the insulation material used in this project, which was characterized optically, the reduction of cooling load is compensated by the increase of artificial lighting demand when replacing a window. 


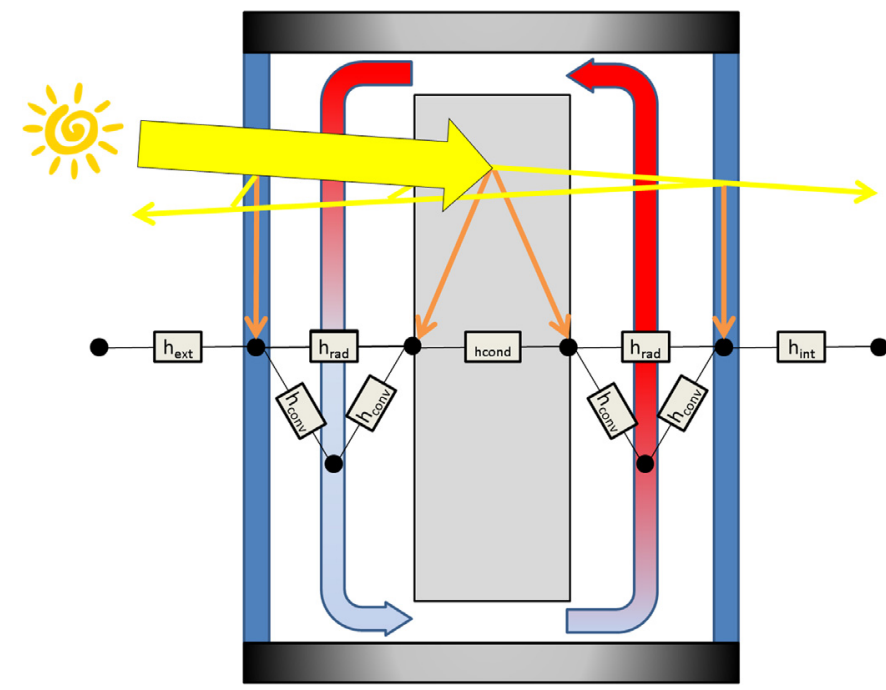

Fig. 2. Schematic drawing of the detailed physical model. The element is in the conducting state. The thermal nodes are represented, as well as the heat transfer coefficients network. The arrows show the solar irradiance which is transmitted or reflected through the system as well as the absorbed solar energy. Multiple optical reflections are not shown. The thermal nodes represent, from left to right, the exterior air temperature, the glass temperature, the average fluid temperature of the outer air column, the outer and inner surface temperatures of the insulation panel, the average fluid temperature of the inner air column, the inner glass temperature and the interior (room) temperature. (For interpretation of the references to color in this figure legend, the reader is referred to the web version of this article.)

For the building simulation results presented in [18], a very simplified model was used for the element, which used linear interpolation between measured U-values and a constant g-value. Both in order to simulate the element's performance under various conditions more precisely and in order to optimize the design of the instrument theoretically in an early phase, a new model has been developed and is presented here. The new model is first introduced, before being validated. Finally, the physical model is used for a parametric calculation to assess the impact of the most important parameters on the element's performance.

\section{Physical model}

The new physical model is based on the coupling of a thermal nodal model, an airflow model and an optical model. The model is represented in a schematic way for the conducting state in Fig. 2. The unknown variables are the temperatures of each node or layer. In the conducting case, three unknown variables are added: the mass flow rate through the system as well as the mean temperatures of the outer and inner air columns. The resulting system of equations was solved using the VBA built-in Excel solver. The main outputs are the U-value and g-value of the element.

The thermophysical model is represented in a simplified way in Fig. 2 in the conducting state.

\subsection{Airflow model}

In this section, the airflow model is briefly presented. For the airflow model, the main hypotheses are:

1. The fundamental hypothesis is that there is a stationary equilibrium between the pressure drops in the system and the density difference (see below) in the system.

2. The convection within each of the two air columns is considered as forced - with the buoyancy force acting as driving pressure - laminar (Re of about 300), and hydrodynamically and thermally not fully developed [18].
3. The fluid outlet temperature of one column is the fluid inlet temperature of the other one. In other words, no thermal exchange occurs at the top and bottom horizontal air layers.

4. A constant Prandtl number of 0.71 was assumed in the whole system, corresponding to air at $20^{\text {circ }} \mathrm{C}$.

5. The mass flow is constant in the system, there are no air leakages. During the construction of the prototypes, particular attention was given to airtightness. For convenience, the mass flow rate is converted in airflow rate $\left(\mathrm{m}^{3} \mathrm{~h}^{-1}\right)$ when presenting results in the following sections.

The fundamental relation of airflow model is that the driving pressure difference is equal to the sum of the pressure drops in the system (hypothesis 1):

$\sum \Delta P_{\text {driving }}=\sum \Delta P_{\text {system }}$

The driving pressure of the convection is due to the difference of density between the internal (1) and external (2) vertical air columns, calculated as:

$\sum \Delta P_{\text {driving }}=g\left[\int_{0}^{H} \rho_{1}(h) \mathrm{d} h-\int_{0}^{H} \rho_{2}(h) \mathrm{d} h\right]$

With:

- $g=9.81\left[\mathrm{~m} \mathrm{~s}^{-2}\right]$ the standard gravity.

- $H[\mathrm{~m}]$ the height of the glazed surface.

- $h[\mathrm{~m}]$ the height along the vertical axis.

- $\rho_{1}(\mathrm{~h})$ and $\rho_{2}(\mathrm{~h})\left[\mathrm{kg} \mathrm{m}^{-3}\right]$ the density of the fluid in the outer and inner air column at height $h$, respectively.

The pressure drop correlations for laminar duct flow in the vertical air columns, for the $90^{\circ}$ elbow and for the change of cross section between vertical and horizontal air gaps have been taken from [19].

\subsection{Thermal model}

For the thermal node model, following hypotheses are made:

1. The surface temperatures of each layer are averaged over the height and are represented by an energy node. The glass layers are represented by one node, the insulation layer by two surfaces nodes.

2. The calculation is steady state (no time-dependency is considered).

3. The convective heat transfer coefficients are constant over the height of the glazed and insulation area.

4. In the inner and outer air column, the fluid is symmetrically heated by the glass and the insulation, as if the convection took place between the fluid and a single wall with an equivalent temperature (mean temperature between both surfaces surrounding the fluid).

5. For the calculation of the g-value, it is assumed that half of the absorbed solar energy in the insulation layer is absorbed at the outer surface and half is absorbed at the inner surface.

6. In the insulating case, the two vertical cavities were considered as two closed air columns. The validity of this hypothesis has been shown during the experimental analysis introduced in [15], with only $2.5 \%$ difference in the insulating state between the insulation panel at the top and an insulation panel going from the top to the bottom without horizontal air gap.

7. The conductive thermal resistance of the front and back covers is neglected.

8. For the radiative longwave exchange, the hypothesis of infinitely long parallel, grey-diffuse surface is made.

9. No distinction was made between the radiative and the air temperature on the inner and the outer surface, and environmental temperatures were used (see below). 
The boundary conditions are given by:

- Internal and external environment temperatures $T_{\text {int }}$ and $T_{\text {ext }}$ $[\mathrm{K}]$.

- Constant internal and external heat transfer coefficients $h_{\text {int }}$ and $h_{\text {ext }}$ of 7.69 and $25 \mathrm{~W} \mathrm{~m}^{-2} \mathrm{~K}^{-1}$, respectively, as given for example in [20] Note that the $h_{\text {ext }}$ value corresponds more to a windy winter situation. To reflect better the reality as well as to be used in a building simulation program, the heat transports to the room and the exterior should be split in radiative and convective heat transfer. However, the use of standard heat transfer coefficients allows the comparison to standard windows and facade elements.

Each layer is represented by one or several energy nodes. For each node, an energy balance is performed to determine the temperature of the node. For example, for a facade element with one insulation layer, in the conducting state, following energy balance is applied to the outer glazing node:

$$
\begin{aligned}
h_{\text {ext }}\left(T_{\text {outer glass }}-T_{\text {ext }}\right) & +h_{\text {rad,outer gap }}\left(T_{\text {outer glass }}-T_{\text {ins.,outer surf. }}\right) \\
& +h_{\text {cvvent, outer gap }}\left(T_{\text {outer glass }}-T_{\text {air, outer gap }}\right) \\
& =I \alpha_{e, \text { sol }, \text { ext.g. }}
\end{aligned}
$$

With:

- $T_{\text {ext }}[\mathrm{K}]$ the external boundary air temperature.

- $T_{\text {outerglass }}[\mathrm{K}]$ the temperature of the outer glass pane.

- $T_{\text {air, outergap }}[\mathrm{K}]$ the average air temperature of the outer air column.

- $T_{\text {ins., outersurf. }}[\mathrm{K}]$ the outer surface temperature of the insulation panel.

- $h_{\text {ext }}\left[\mathrm{W} \mathrm{m}^{-2} \mathrm{~K}^{-1}\right]$ the external boundary heat transfer coefficient.

- $h_{\text {rad, outergap }}\left[\mathrm{W} \mathrm{m}^{-2} \mathrm{~K}^{-1}\right]$ the radiative heat transfer coefficient between the outer glass and the outer surface of the insulation layer.

- $h_{c v}$, vent, outergap $\left[\mathrm{W} \mathrm{m} \mathrm{m}^{-2} \mathrm{~K}^{-1}\right]$ the average convective heat transfer coefficient between the outer air gap and the outer surface of the insulation layer, in case of a ventilated cavity, as defined below.

- $I\left[\mathrm{~W} \mathrm{~m} \mathrm{~m}^{-2}\right]$ the total solar irradiance arriving at the element's outer surface.

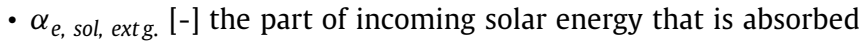
in the external glass layer.

In the open, conducting case, the vertical air columns enclosed between the insulation panels and the glass panes are considered as ventilated ducts. The hypotheses made above lead to a differential equation resulting in an exponential temperature profile in each column. This method is presented for example in the standard ISO15099 [21]. The Nusselt number in the gap, characterizing the convective heat transfer between the air and the two limiting surfaces, is calculating using following correlation for laminar forced convection in the entrance region of a parallel-plate duct with uniform temperature [22]:

$N u=7.55+\frac{0.024\left(\left(\operatorname{RePr} \frac{D_{h}}{H}\right)\right)^{1.14}}{1+0.0358\left(\left(\operatorname{RePr} \frac{D_{h}}{H}\right)\right)^{0.64} \operatorname{Pr}^{0.17}}$

And the convective heat transfer between the air column's surface and the fluid is given by:

$h_{c v}=\frac{N u \lambda}{D_{h}}$

With:

- $\operatorname{Pr}[-]$ the Prandtl Number of the fluid.

- $H[\mathrm{~m}]$ the height of the vertical air channel.
- $\operatorname{Re}[-]$ the Reynold Number in the gap.

- $\lambda\left[\mathrm{W} \mathrm{m}^{-1} \mathrm{~K}^{-1}\right.$ ] the thermal conductivity of the gas at the cavity average fluid temperature.

- $D_{h}[\mathrm{~m}]$ the hydraulic diameter of the gap.

The laminar and forced nature of the flow has been investigated in [18]. During the validation process, the validity of the hypothesis of symmetrical heating between the fluid and two surface at identical temperatures is discussed.

In the insulating case, the two vertical cavities were considered as two closed air columns. The correlation introduced by Wright [23] for closed-cavity convection is then used.

For the elements with two insulation layers separated by a thin vertical air column, this air column was also considered as a closed cavity, both in the conducting and insulating state.

Finally, following correlation was used to calculate the radiative longwave heat transfer coefficients between two infinite parallel, grey-diffuse surfaces [24]:

$h_{\text {rad }}=\sigma \frac{1}{\frac{1}{\epsilon_{1}}+\frac{1}{\epsilon_{2}}-1}\left(\frac{T_{1}^{4}-T_{2}^{4}}{T_{1}-T_{2}}\right)$

With:

- $\sigma=5.67 * 10^{-8}\left[\mathrm{~W} \mathrm{~m} \mathrm{~m}^{-2} \mathrm{~K}^{-4}\right]$ the Stefan-Boltzmann constant.

- $\epsilon_{1}, \epsilon_{2}[-]$ the longwave emissivities of both surfaces.

- $T_{1}, T_{2}[\mathrm{~K}]$ the temperature of both surfaces.

After solving the system of equations, the U-value was calculated as follow [21]:

$U=\frac{q_{\text {int }}(I=0)}{T_{\text {ext }}-T_{\text {int }}}$

$q_{\text {int }}(I=0)\left[\mathrm{W} \mathrm{m}^{-2}\right]$ being the total heat flux from the interior glass pane towards the room by convection, conduction and longwave radiation, in the absence of solar irradiance, defined as:

$q_{\text {int }}=h_{\text {int }}\left(T_{\text {innerglas }}-T_{\text {int }}\right)$

With:

- $h_{\text {int }}=7.69\left[\mathrm{~W} \mathrm{~m}^{-2} \mathrm{~K}^{-1}\right]$ the internal boundary heat transfer coefficient, as defined for example by [20]

- $T_{\text {innerglass }}[\mathrm{K}]$ the inner glass pane temperature

- $T_{\text {int }}[\mathrm{K}]$ the interior environment temperature

- $T_{\text {ext }}[\mathrm{K}]$ the exterior environment temperature

For the purpose of the parametric analysis, the U-value with the constant boundary heat transfer coefficients to the interior and exterior environment allows the comparison between different variants.

\subsection{Optical model}

In order to calculate the g-value, the part of the incoming solar radiation absorbed in each layer as well as the transmitted solar radiation has to be calculated. For that purpose, the angle-dependent and thickness-dependent optical properties of the translucent insulation material have been characterized optically in [18]. For the glass cover, the optical values in the visible and solar spectrum range are taken for $3 \mathrm{~mm}$ clear glass from [25].

For the optical part of the model, following hypotheses were used:

1. The incoming solar energy is fully diffuse for the parametric analysis presented in this paper, the consequence being that hemispherical-hemispherical transmittance and reflectance values can be used for the glass and translucent insulation layers. 
Table 1

Optical properties of the facade element. $d_{\text {insu. }}$ is the thickness of the insulation layer. The three decimals do not indicate the accuracy of the model but are shown to illustrate slight differences.

\begin{tabular}{lllll}
\hline $\mathrm{d}_{\text {insu. }}$ & $\tau_{h h}$ & $\alpha_{e, \text { sol, ext glass }}$ & $\alpha_{e, \text { sol, trans.insu. }}$ & $\alpha_{e, \text { sol, int glass }}$ \\
\hline $\mathrm{mm}$ & - & - & - & - \\
5 & 0.184 & 0.168 & 0.096 & 0.027 \\
10 & 0.092 & 0.185 & 0.074 & 0.014 \\
15 & 0.048 & 0.189 & 0.087 & 0.007 \\
20 & 0.033 & 0.192 & 0.087 & 0.005 \\
30 & 0.032 & 0.192 & 0.088 & 0.005 \\
\hline
\end{tabular}

2. In the absence of angle-dependent measurement data for translucent insulation material with thicknesses different from $15 \mathrm{~mm}$, the ratio between the direct-hemispherical values measured at $60^{\circ}$ and the hemispherical-hemispherical values is assumed constant for all thicknesses and equal to the one for $15 \mathrm{~mm}$ as shown in [18].

3. The integral values according to [26] have been used, assuming that the optical properties do not strongly vary with the wavelength. To get a slightly better accuracy, wavelength-dependent values could be used.

In order to calculate the part of the incoming solar energy absorbed in each layer, the standard EN410 [26] method was chosen. This standard proposes an analytical solution for the solar energy transmitted through a facade element composed by three layers, taking into account the multiple reflections between layers. This results for example in following equation for the total solar energy absorbed in the outer glazing, after multiple reflections:

$\alpha_{e, s o l, e x t g .}=\alpha_{h h, g}$

$$
+\frac{\tau_{h h, g .} \alpha_{h h, g .} \rho_{h h, t . i .}\left(1-\rho_{h h, t . i .} \rho_{h h, g .}\right)}{\left(1-\rho_{h h, t . i .} \rho_{h h, g .}\right)^{2}-\tau_{h h, t . i .}{ }^{2} \rho_{h h, g .}{ }^{2}}
$$

With:

- $\tau_{h h, g .}$ [-] the hemispherical-hemispherical transmittance value of float glass. A value of 0.753 was assumed [25]. It is assumed that this value is the same for both directions of light. Exceptions for which the transmittance is different for the two directions can for example be seen in [27].

- $\tau_{\text {hh, t.i. }}[-]$ the hemispherical-hemispherical transmittance value of the translucent insulation layer. This thickness-dependent value was calculated as explained above.

- $\rho_{h h, g .}$ [-] the hemispherical-hemispherical reflectance value of float glass. A value of 0.136 was assumed [25]. To be used with glass with different optical properties on both sides, the formulas could be extended according to [26].

- $\rho_{\text {hh, t.i. }}$ [-] the hemispherical-hemispherical reflectance value of the translucent insulation layer. This thickness-dependent value was calculated as explained above.

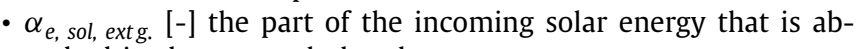
sorbed in the external glass layer.

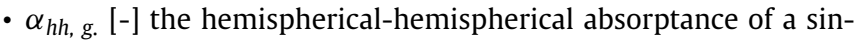
gle glass pane, assuming that the following equation is valid for the single glass pane: $\alpha_{h h, g .}=1-\tau_{h h, g .}-\rho_{h h, g .}$.

The resulting thickness-dependent values for the whole facade element are shown in Table 1. With:

- $\tau_{h h}$ [-] the hemispherical-hemispherical overall transmittance of the combination of glass panes and insulation material, frame and edge effects being neglected.

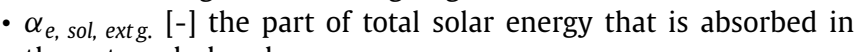
the external glass layer.

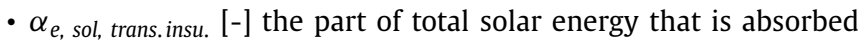
in the translucent insulation layer.

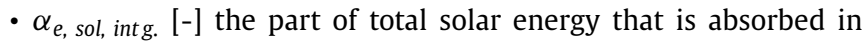
the internal glass layer.

The part of total solar energy absorbed is much higher in the outer glass layer than in the translucent insulation layer and the internal glass layer, due to the high solar reflection of the translucent insulation layer. While the absolute value of the total solar irradiance absorbed in each layer doesn't vary much with the thickness, the thickness of the insulation layer has a major impact on the solar transmission, with values going from about 0.18 to 0.03 . This low overall transmittance is explained by the transmittance of the translucent insulation layer, which varies from 0.27 for $5 \mathrm{~mm}$ thickness to 0.04 for $30 \mathrm{~mm}$ [18].

The g-value is then calculated as follow [21]:

$g=\frac{\tau_{h h} I+q_{\text {int }}-q_{\text {int }}(I=0)}{I}$

With:

- $I\left[\mathrm{~W} \mathrm{~m} \mathrm{~m}^{-2}\right]$ the total irradiance arriving at the element's outer surface.

- $q_{\text {int }}\left[\mathrm{W} \mathrm{m} \mathrm{m}^{-2}\right]$ the total heat flux from the interior glass pane towards the room by convection, conduction and longwave radiation, as defined in Eq. (8).

- $\tau_{h h}[-]$ the hemispherical-hemispherical transmittance as defined above.

\section{Validation with experimental data}

\subsection{Experimental data}

The closed facade element was investigated experimentally in depth in [15] and [18]. In this section, the experimental data used for the validation are briefly summarized.

For the U-value measurement, the Taurus equipment at Fraunhofer ISE was used. The Taurus equipment is a hot plate apparatus in accordance with [28]. As a difference to the standard, instead of using two samples for each measurement, the second sample was replaced by a reference sample, consisting of a $40 \mathrm{~mm}$ thick insulating Styropor plate. This was taken into account for the uncertainty calculation. The total thermal resistance measured by the apparatus is converted to U-value by adding the two boundary thermal resistances to the exterior and the interior environment, which are $0.04 \mathrm{~m}^{2} \mathrm{~K} \mathrm{~W}^{-1}$ and $0.13 \mathrm{~m}^{2} \mathrm{~K} \mathrm{~W}^{-1}$, respectively, as defined for example in [26].

The measured values are center of glazing values, the heat flux being measured over a $500 * 500 \mathrm{~mm}^{2}$ central area, and the prototype area being $800 * 800 \mathrm{~mm}^{2}$. For the U-value measurements considered, the maximal absolute uncertainty was $0.040 \mathrm{~W} \mathrm{~m} \mathrm{~m}^{-2} \mathrm{~K}^{-1}$, the minimal absolute uncertainty was $0.017 \mathrm{~W} \mathrm{~m}^{-2} \mathrm{~K}^{-1}$ and the mean absolute uncertainty was $0.031 \mathrm{~W} \mathrm{~m}^{-2} \mathrm{~K}^{-1}$.

Seven different geometrical configurations were investigated, each of them being measured with two temperature differences applied at the prototype's inner and outer surfaces: a low one of about $15 \mathrm{~K}$, and a higher one of about $30 \mathrm{~K}$. The goal was to capture the temperature dependency of the thermophysical effects at stake. The glazed surface of the prototypes was $0.76 * 0.76 \mathrm{~m}^{2}$. All test models were composed of two $3 \mathrm{~mm}$ thick Poly(methyl methacrylate) (PMMA) panes (replacing glass for practical purposes), a $20 \mathrm{~mm}$ thick PVC frame at the top and bottom and one or several translucent insulation panel. The test models were all measured in a vertical position. The U-value measurements used for validation are briefly summarized in Table 2. For consistency purpose, the measurement number refers to the numbers used in $[15,18]$.

For this set of measurements, no temperature sensor was placed in the measured prototypes. A second measurement cam- 
Table 2

Measured U-values in different geometrical configurations and with different temperature differences at the boundaries. $\mathrm{C}=$ conducting state, $\mathrm{I}=$ insulating state. $\mathrm{A}, \mathrm{B}, \mathrm{C}$ and $\mathrm{D}$ are the thickness of the vertical air layers, the thickness of the translucent insulation layer, the dimension of the upper air gap and the dimension of the lower air gap, respectively. $\theta_{\text {mean }}$ is the mean temperature between the two boundaries.

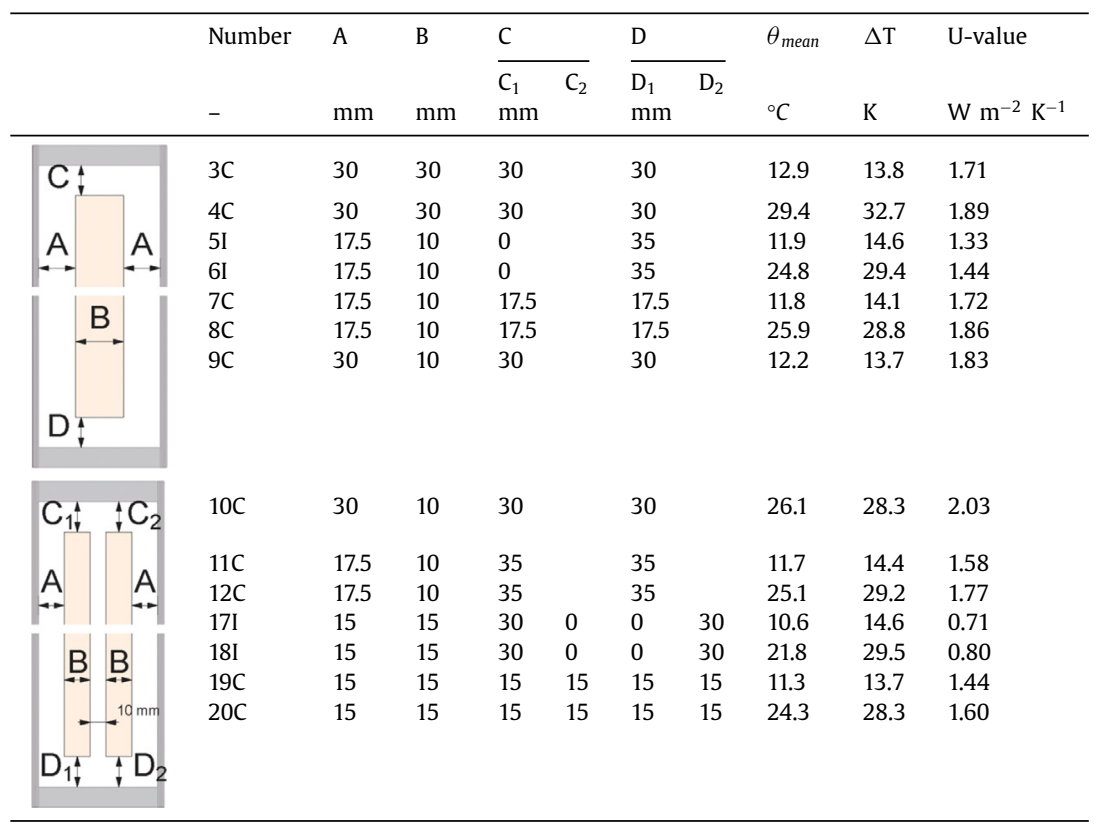

paign was performed on a single-panel prototype, covering differences of temperatures between the outer pane and the inner pane between 1 and $30 \mathrm{~K}$, and for which the center-of-glazing temperatures of the different layers in the prototype as well as air column temperatures were measured at middle vertical height.

An extensive discussion of the measurement results is available in $[15,18]$.

\subsection{Validation}

In a first validation step, the calculated $U$-value of the element has been compared to the measured one for the different cases presented in Table 2 . The airflow rate in the prototype was not measured.

To match the model's boundaries to the boundaries of the Taurus measurement apparatus, which are the inner and outer surface temperature instead of the inner and outer environment temperature, the model output U-value was calculated as follow for the validation:

$U=\frac{1}{\frac{T_{\text {ext }}-T_{\text {int }}}{q_{\text {int }}(I=0)}+\frac{1}{h_{\text {int }}}+\frac{1}{h_{\text {ext }}}}$

With:

- $h_{\text {int }}=7.69\left[\mathrm{~W} \mathrm{~m} \mathrm{~m}^{-2} \mathrm{~K}^{-1}\right]$ the internal boundary heat transfer coefficient, as defined for example by [20]

- $h_{\text {ext }}=25\left[\mathrm{~W} \mathrm{~m} \mathrm{~m}^{-2} \mathrm{~K}^{-1}\right]$ the external boundary heat transfer coefficient, as defined for example by [20]

- $T_{\text {int }}[\mathrm{K}]$ the interior environment temperature.

- $T_{\text {ext }}[\mathrm{K}]$ the exterior environment temperature.

To compare the value calculated by the model to the measured value which is measured at the center of the surface, $q_{\text {int }}$ is calculated as follow in the conducting case:

$q_{\text {int }}=h_{c v, \text { vent,innergap }}\left(T_{\text {gas,inner gap }}\left(\frac{H}{2}\right)-T_{\text {inner glass }}\right)$

$$
+h_{\text {rad,inner gap }}\left(T_{\text {ins.,inner surf. }}-T_{\text {inner glass }}\right)
$$

And in the insulating case:

$q_{\text {int }}=\left(h_{c v, \text { closed,innergap }}+h_{\text {rad,inner gap }}\right)\left(T_{\text {ins.,inner surf. }}-T_{\text {inner glass }}\right)$

With:

- $T_{\text {gas, innergap }}(H / 2)[\mathrm{K}]$ the temperature at the middle height in the inner air column.

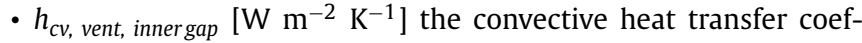
ficient in the inner vertical gap in case of ventilated cavity.

- $h_{c v, \text { closed, innergap }}\left[\mathrm{W} \mathrm{m} \mathrm{m}^{-2} \mathrm{~K}^{-1}\right]$ the convective heat transfer coefficient in the inner vertical gap in case of closed cavity.

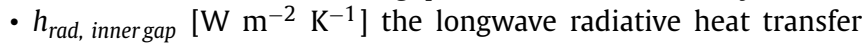
coefficient in the inner vertical gap.

- $T_{\text {innerglass }}[\mathrm{K}]$ the inner glass pane temperature.

- $T_{\text {ins., innersurf. }}[\mathrm{K}]$ the inner surface temperature of the insulation panel.

In this part, inner refers to the warm, heated side and outer refers to the cold side.

The model can now be compared to the measured cases presented in Table 2, as shown in Fig. 3.

For this 7 different geometries and insulating state, the Root Mean Square Error (RMSE) is $0.183 \mathrm{~W} \mathrm{~m}^{-2} \mathrm{~K}^{-1}$ and the mean difference is $9.5 \%$, mainly due to cases $7 \mathrm{C}, 8 \mathrm{C}, 11 \mathrm{C}$ and $12 \mathrm{C}$. Without cases $11 \mathrm{C}$ and $12 \mathrm{C}$, the RMSE drops to $0.127 \mathrm{~W} \mathrm{~m}^{-2} \mathrm{~K}^{-1}$ and the mean difference drops to $6.3 \%$.

The laminar flow conditions are still largely verified in the conducting state, with calculated Reynolds numbers in the vertical gaps going from 203 to 412 and airflow going from 4.1 to $9.5 \mathrm{~m}^{-3}$ $\mathrm{h}^{-1}$ for the 10 cases in the conducting state.

Cases 7C, 8C and 19C, 20C show an overestimation of the Uvalue which increases with the temperature difference in the conducting state. These four cases in the conducting case have the lowest thickness of vertical air gaps, with thickness of $17.5 \mathrm{~mm}$ for cases $7 \mathrm{C}$ and $8 \mathrm{C}$ and $15 \mathrm{~mm}$ for cases $19 \mathrm{C}$ and 20C. For these four 


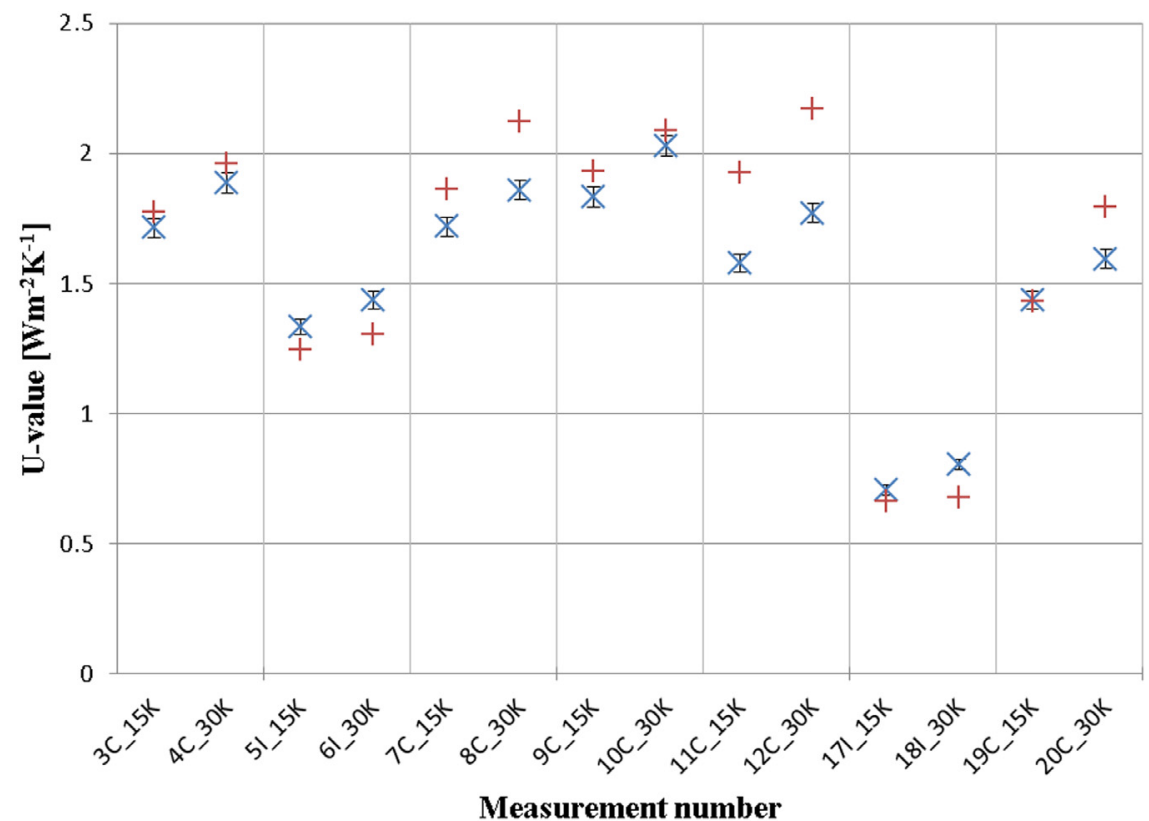

$\times$ U-value, measured + U-value, simulated

Fig. 3. Measured versus calculated U-values. $C=$ conducting state, $I=$ insulating state.

cases $7 \mathrm{C}, 8 \mathrm{C}, 19 \mathrm{C}$ and $20 \mathrm{C}$, the relative difference is of $8.3 \%, 14.2 \%$, $0.4 \%$ and $12.4 \%$, respectively. These differences are discussed further in this section.

Cases $11 \mathrm{C}$ and $12 \mathrm{C}$ show the most important differences between measurements and model, with $21.1 \%$ and $21.5 \%$ relative differences, respectively. For these two cases, the height of the horizontal air gap $(35 \mathrm{~mm})$ at the top and bottom of the element is twice larger than the thickness of the vertical air gaps $(17.5 \mathrm{~mm})$. However, the model is capable to simulate larger horizontal air gaps with a higher accuracy if the hydraulic diameters of the horizontal air gaps and the vertical air gaps are the same, as shown by cases 3C, 4C, 9C and 10C. It appears than that the difference appearing for cases $11 \mathrm{C}$ and $12 \mathrm{C}$ are a consequence of this change of hydraulic diameter between the vertical and horizontal air gaps. Despite the fact that the pressure drops due to the enlargement or reduction of cross section were taken into account [19], the pressure drops seem to be underestimated in this case.

The model results 3C, 4C, 9C and $10 \mathrm{C}$ show good agreement with the measurements, with a RMSE of $0.073 \mathrm{~W} \mathrm{~m}^{-2} \mathrm{~K}^{-1}$ over these four situations and a maximum relative difference of $3.3 \%$ for measurement $11 \mathrm{C}$. The prototypes in these measurements have a thickness of the vertical air gaps of $30 \mathrm{~mm}$, and the insulation panel is either $10 \mathrm{~mm}$ or $30 \mathrm{~mm}$ thick.

The cases in the insulating state (5I, 6I and 17I, 18I) are modelled with a satisfying accuracy, the RMSE for this four cases being $0.103 \mathrm{~W} \mathrm{~m}^{-2} \mathrm{~K}^{-1}$ while the maximum relative difference is $15.5 \%$ for case 18 I. The slight underestimation can be partially explained by the fact that the model in the insulating state consider the vertical cavities as completely closed with no mass transfer between the outer and inner cavities, while in reality a low mass transfer occur at the bottom of the element.

The cases with two insulation panels (17I, 18I, 19C, 20C) are the same prototype in insulating (17I, 18I) and conducting state (19C, 20C). It is composed by outer and inner vertical air gaps of $15 \mathrm{~mm}$ thickness, two insulation panels of $15 \mathrm{~mm}$ thickness and an insulating air gap of $10 \mathrm{~mm}$ thickness in the middle between the two insulation panels. For this geometry with two insulation panel and thin vertical air gaps, the same conclusions can be drawn than for the single insulation layer prototypes: the model slightly underestimates the U-value in the insulating case, and slightly overestimates it in the conducting case.

A second measurement campaign was performed on a singlepanel prototype, covering differences of temperatures between the outer pane and the inner pane between 1 and $30 \mathrm{~K}$. For this second measurement campaign, the prototype was equipped with a single insulation panel in a conducting state. From outside to inside, there was a $15 \mathrm{~mm}$ vertical air layer, a $15 \mathrm{~mm}$ insulation layer and again a $15 \mathrm{~mm}$ vertical air layer. The height and width of the glazed area was $760 * 760 \mathrm{~mm}^{2}$. The height of the insulation panel was $730 \mathrm{~mm}$, and the height of the top and bottom air gaps were $15 \mathrm{~mm}$. The measurement results of this prototype in the conducting case are compared against the detailed model in Fig. 4.

For these 9 different temperature differences at the boundary, the RMSE is $0.08 \mathrm{~W} \mathrm{~m} \mathrm{~m}^{-2} \mathrm{~K}^{-1}$ while the mean relative difference between model and measurement is $19 \%$. For this geometrical configuration, the model is overestimating the heat transfer and the difference increases with the difference in temperature, with a maximal relative difference of $29.9 \%$ for a temperature difference of $29.4 \mathrm{~K}$.

4 PT100 temperature sensors were also used to measure at middle vertical height the air temperature in the vertical outer and inner air channel, and the inner and outer surface temperatures of the insulation panel. While the model shows good agreement with the temperature measurement for the outer air gap and outer surface of the insulation layer, the model overestimates the air temperature in the inner, warm air gap. As a consequence, the temperature of the inner surface of the insulation layer is also overestimated. The difference increases with temperature. This difference in the air gap temperature for high temperature differences explains the overestimating of the U-value. Taking for example the inner, warm air gap: for this measurement with thin insulation thickness $(15 \mathrm{~mm})$ the air in the inner gap is heated from the PMMA plate side and cooled from the insulation side. For example, for a temperature difference of $29.4 \mathrm{~K}$ applied at the boundaries of the prototype, the air at middle vertical height is 8.1 $\mathrm{K}$ colder than the PMMA surface. In the same time, the air 


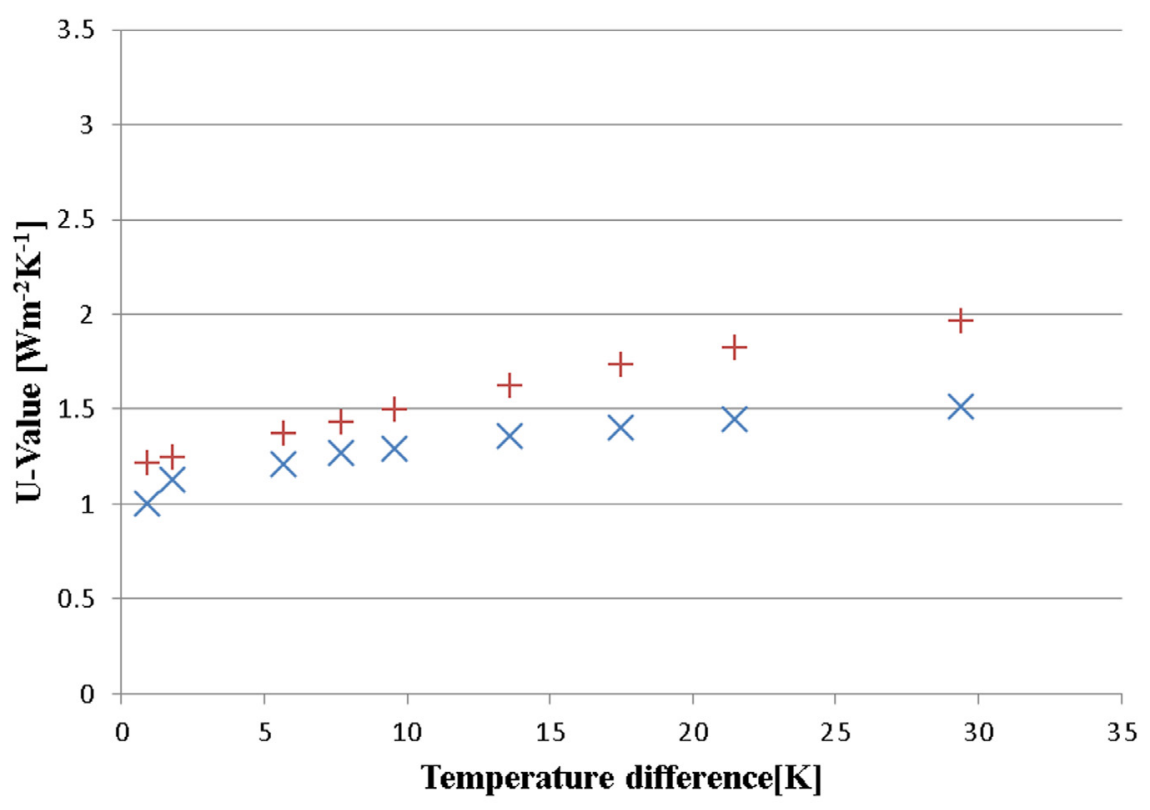

$\times$ U-value, measured $\quad+$ U-value, simulated

Fig. 4. Measured versus calculated U-value for several temperature differences.

is $2.3 \mathrm{~K}$ warmer than the insulation inner surface. The hypothesis that the fluid is heated from both surrounding parallel plates at a uniform temperature is no longer true since the air is cooled from one side and slightly heated from the other.

In the above cases $7 \mathrm{C}, 8 \mathrm{C}, 11 \mathrm{C}, 12 \mathrm{C}, 13 \mathrm{C}, 14 \mathrm{C}$, the convective heat transfer coefficient between insulation and fluid is high due to the low hydraulic diameters, according to Eq. (5). Furthermore, the temperature of the insulation surface is closer to the average fluid temperature. Also, for cases $7 \mathrm{C}$ and $8 \mathrm{C}$ as well as the measured case with multiple temperature difference, the low thickness of the insulation layer increases the effect since the conduction through the insulation decreases the insulation inner surface temperature, which is then even nearer to fluid temperature, or below. For example, for case $8 \mathrm{C}$ with $17.5 \mathrm{~mm}$ thick vertical air gaps and insulation layer, the results of the detailed model, assuming symmetric heating between the fluid and walls that have an identical uniform temperature, shows us that the convective heat flux going from the insulation inner surface towards the air column is of $8.8 \mathrm{~W} \mathrm{~m}^{-2}$. The model also shows that in this case the convective heat flux going from the inner PMMA surface towards the air column is of $60.2 \mathrm{~W} \mathrm{~m}^{-2}$, showing a very strong asymmetrical heating situation resulting from an important temperature difference between outer cover and insulation panel. In the cases 3C, 4C with more important thickness of the vertical air gaps and larger insulation thickness, the insulation surface temperature in the inner gap is warmed by the inner cover pane by longwave radiation. For example, in case $4 \mathrm{C}$, the convective heat flux insulation-fluid in the inner gap is of $25.0 \mathrm{~W} \mathrm{~m} \mathrm{~m}^{-2}$, while the convective heat flux fluidPMMA plate is of $53.9 \mathrm{~W} \mathrm{~m}^{-2}$ and the radiative heat flux between the two surfaces $43.8 \mathrm{~W} \mathrm{~m}^{-2}$. In these cases there is a better agreement between simulation and measurements.

For the last measurement with numerous temperature differences at the boundaries (Fig. 4), the inner air column is even heated at the PMMA plate side and slightly cooled at the insulation side. In the case of asymmetric heating or cooling at one side and heating at the other, the Nusselt numbers and so the heat transfer coefficients are different at both sides of the duct. In the literature, only a few correlations are given to calculate dif- ferent Nusselt numbers at both sides, as stated by Gloriant [29]. In [30] a method is presented, which has been further investigated by Nield [31] (corrected by [32]) but this method is only valid for constant heat flux boundaries. For asymmetrically heated parallel-plate ducts and ducts heated from one side and cooled from the other, correlations are proposed by Schwab [33] based on experimental work. However, these correlations are only valid for $380<\operatorname{Re}<2900$, and the models presented here shows that the Reynolds number in the present study are often lower. Another approach is to pre-calculate the convective heat transfer coefficients at both sides of the air columns with a CFD calculation for the range covered by the simple model, as suggested by Gloriant [29], and then insert these correlations in the current model.

For the purpose of the parametric analysis, it has been chosen to continue with the hypothesis of symmetrical heating between the fluid and a single surface at equivalent temperature due to the acceptable accuracy of the model in most cases, but being aware that the model overestimates the U-value for low hydraulic diameters and low insulation thickness, and that the difference increases with the temperature difference at the boundary. A more detailed discussion concerning this assymetric heating situation is available in [18]. Possible ameliorations of the model are discussed in the conclusion of this paper.

\section{Results: parametricanalysis}

The physical model was then used for a parametrical analysis. The goal was to investigate the impact of the thermophysical and geometrical parameters on the element performance. The method used is One-At-a-Time (OAT): while one parameter is varied, the others are maintained constant.

For this parametric analysis, a summer situation was chosen. The exterior environment temperature is below the interior one, corresponding to a case where the element would be switched to the conducting state to cool down the building. Following boundary conditions were then used:

- Room air temperature: $26^{\circ} \mathrm{C}$

- Exterior air temperature: $16^{\circ} \mathrm{C}$ 
Table 3

Parameters investigated within the parametric analysis. $\mathrm{H}$ and $\mathrm{W}$ are the height and width of the glazed area and the vertical air gap. $\mathrm{d}_{\text {insu. }}$ and $\mathrm{d}_{\text {verti.airgaps }}$ are the thicknesses of the insulation layer and the vertical air gaps, respectively. $\lambda_{\text {insu. }}$ is the thermal conductivity of the insulation layer.

\begin{tabular}{lllll}
\hline Name & Unit & Range & Step & Reference value \\
\hline $\mathrm{H}$ & $\mathrm{m}$ & {$[0.4-5]$} & 0.1 & 0.76 \\
$\mathrm{~W}$ & $\mathrm{~m}$ & {$[0.4-5]$} & 0.1 & 0.76 \\
$\mathrm{~d}_{\text {insu. }}$ & $\mathrm{m}$ & {$[0.005-0.03]$} & 0.005 & 0.030 \\
$\mathrm{~d}_{\text {verti. airgaps }}$ & $\mathrm{m}$ & {$[0.01-0.10]$} & 0.002 & 0.030 \\
$\lambda_{\text {insu. }}$ & $\mathrm{W} \mathrm{m}^{-1} \mathrm{~K}^{-1}$ & {$[0.005-0.25]$} & 0.005 & 0.035 \\
\hline
\end{tabular}

- Interior boundary heat transfer coefficient: $7.69 \mathrm{~W} \mathrm{~m}-2 \mathrm{~K}^{-1}$.

- Exterior boundary heat transfer coefficient: $25 \mathrm{~W} \mathrm{~m}^{-2} \mathrm{~K}^{-1}$.

- Solar irradiance incoming at the element's outer surface: for each case, two simulations were performed:

- A night case, for the calculation of the U-value: no solar irradiance.

- A diurnal case, for the calculation of the g-value: $500 \mathrm{~W} \mathrm{~m}^{-2}$ direct irradiance on the facade were assumed with $60^{\circ}$, incidence angle or diffuse irradiance. Note that the cases with solar irradiance has not be validated experimentally.

The main calculated outputs for the case with solar irradiance are the g-value and the element's internal glass pane temperature. In the case without solar irradiance, the U-value is monitored. The results are displayed for the element in the insulating state and conducting state. The U- and g-values can then be easily compared to conventional facade systems.

The reference, with $30 \mathrm{~mm}$ thick vertical air layers and one $30 \mathrm{~mm}$ thick insulation layer, was chosen as a starting point since the validation showed a low relative difference of about $3 \%$ on the $\mathrm{U}$-value between model and simulation for this case. This was also the geometry simulated in the building simulation presented in [15].

The parameters investigated are detailed in Table 3.

The hydraulic diameters of the vertical and horizontal air gaps are always identical. The g-value is given with three decimal numbers to show slight differences between variants, but this is no indication of the accuracy of the model.

\subsection{Height of the glazed area and of the vertical air gap}

For these simulations, the height of the glazed area, which is also the height of the vertical air gaps, is varied. The height of the horizontal top and bottom air layers is kept constant $(3 \mathrm{~cm})$, and so the height of the insulation layer varies accordingly to the one of the glazed area (minus $6 \mathrm{~cm}$ ). The results are shown in Fig. 5 .

In the conductive case, while the airflow increases from 3.1 to $19.1 \mathrm{~m}^{3} \mathrm{~h}^{-1}$ due to the increasing chimney effect, the airflow rate relative to the glazed surface area decreases from 10.1 to $5.0 \mathrm{~m}^{3}$ $\mathrm{h}^{-1} \mathrm{~m}^{-2}$, and so the U-value diminishes. In other words, when the height increases, the facade element is less efficient per square meter to evacuate the heat from the room.

For the case with irradiance, the airflow rate is slightly lower: due to absorbed solar energy, the difference of temperature between inner glass temperature and outer glass temperature is less important since more solar energy is absorbed at the outer glass layer and outer surface of the insulation layer. For example, for $5 \mathrm{~m}$ height, the inner and outer glass temperatures are $27.6^{\circ} \mathrm{C}$ and $21.2^{\circ} \mathrm{C}$, respectively, with solar irradiance and $24.1^{\circ} \mathrm{C}$ and $16.7^{\circ} \mathrm{C}$ without solar irradiance. With solar irradiance, the airflow rate increases from 2.9 to $17.3 \mathrm{~m}^{3} \mathrm{~h}^{-1}$ when the height increases from 0.4 to $5 \mathrm{~m}$. The relative increase of the airflow rate with or without irradiance is about the same, and so is the variation of the internal glass pane temperature. This explains an almost constant g-value of about 0.086 when the height of the glazed area is increased.

In the insulating case, the U-value remains constant around $0.72 \mathrm{~W} \mathrm{~m}^{-2} \mathrm{~K}^{-1}$ in the case without solar irradiance. The vertical air gaps are not large enough to allow a large scale internal convection. With solar irradiance, the g-value is also almost constant at 0.082 . For this insulation thickness of $3 \mathrm{~cm}$, the hemisphericalhemispherical solar transmittance calculated for the element was 0.032 and the secondary heat gain was 0.05 in that case.

Finally, it can be remarked that for large heights of the glazed area, the hypothesis of constant surface temperatures may be far from reality, in particular for the insulation material with low thermal conductivity of the layers. For the insulation layer, due to the low thermal conductivity, it is true that the vertical temperature distribution could vary significantly. In the entrance part of the column, the temperature difference and so the heat exchange between the insulations surface and the fluid is maximum. This is at least partially compensated by the heat exchange at the outlet (top or bottom) of the air column, where the temperature difference is minimum. The same applies also to the PMMA layer. A further amelioration step would be to have a vertical discretization of the air and layer volumes, but this is beyond the scope of this research.

\subsection{Width of the glazed area and vertical air gap}

Varying the width of the glazed area between 0.4 and $5 \mathrm{~m}$ has no significant influence on the main outputs: in the conductive state, the width has only little influence on the U-value, which has an almost constant value of about $1.75 \mathrm{~W} \mathrm{~m}^{-2} \mathrm{~K}^{-1}$. With solar irradiance, the g-value keeps the same value of 0.086 . In the insulating state, both the U-value and the g-value are constant with values of $0.72 \mathrm{~W} \mathrm{~m}^{-2} \mathrm{~K}^{-1}$ and 0.082 , respectively.

\subsection{Thickness of the translucent insulation layer}

In this part, the thickness of the vertical air gaps is constant $(3 \mathrm{~cm})$ and the thickness of the translucent insulation layer is varied. For this variation of the insulation layer's thickness, the absorbed solar energy in case of solar irradiance varies strongly with the thickness of insulation, as calculated by the optical model. The influence of the insulation thickness on the U-value is similar to the influence of the variation of the thermal conductivity which is presented later. The influence of the insulation's thickness on the g-value is shown in Fig. 6.

The g-value varies strongly with the thickness of the insulation layer. It can be observed that the g-values in insulating and conducting state are almost equal. The g-value in the conducting state is only very slightly higher. An important part of the incoming solar irradiance is absorbed at the outer glass pane and the outer surface of the insulation, increasing their temperature. The consequence is that the temperature difference between inner and outer air column is lower, and so is the driving force for the airflow rate in the conducting state. In the conducting state, the airflow rate is then lower with solar irradiance. This explains why the difference in g-value is so low compared to the insulating state.

\subsection{Thickness of the vertical air gaps}

In this part, the thickness of the outer and inner air columns is varied. The hydraulic diameter of the top and bottom horizontal air gaps is maintained identical to the one of the vertical air gaps. The results are shown in Fig. 7.

In the conducting state, without irradiance, the Reynolds number increases with the thickness of the gaps, going from 57 for $1 \mathrm{~cm}$ to 479 for $10 \mathrm{~cm}$ in the outer gap for example. However, the 


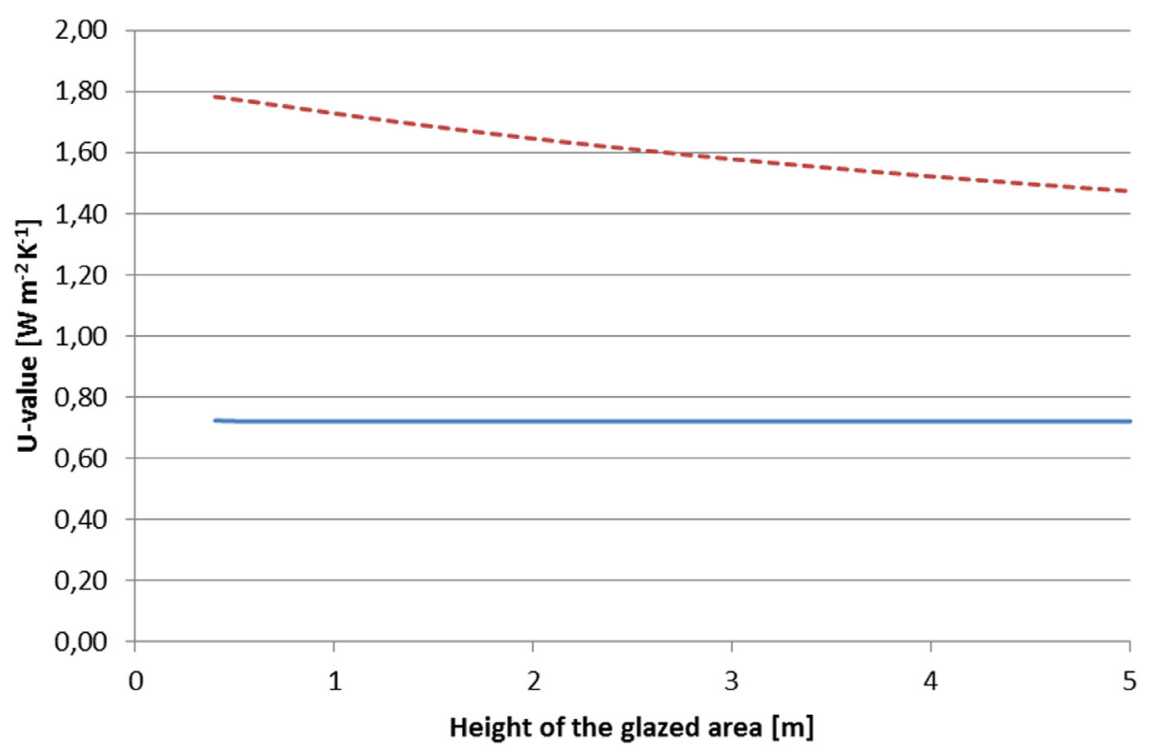

- U-value, insulating state -----U-value, conducting state

Fig. 5. U-value versus height of the glazed area and vertical air gaps, without solar irradiance.

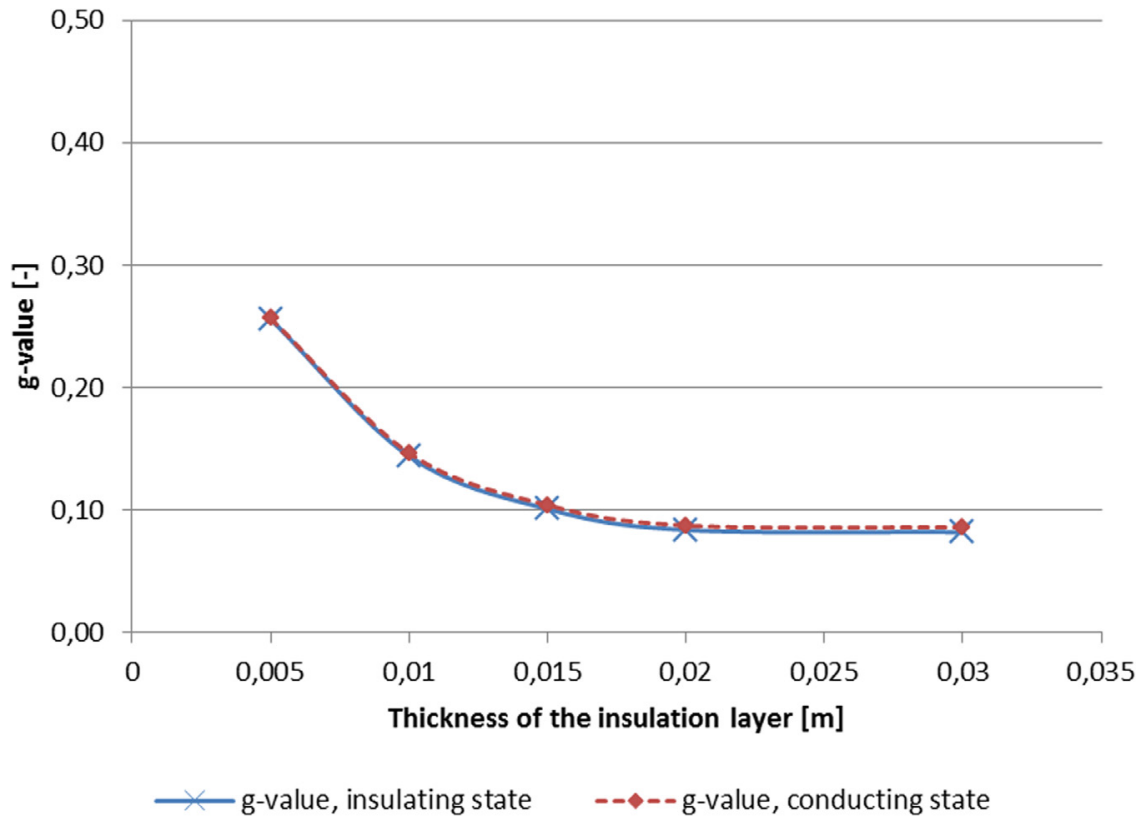

Fig. 6. g-value in the insulating and conducting state versus thickness of the insulation layer.

convective heat transfer coefficients decreases from $9.9 \mathrm{~W} \mathrm{~m}^{-2} \mathrm{~K}^{-1}$ for $1 \mathrm{~cm}$ to $1.4 \mathrm{~W} \mathrm{~m} \mathrm{~m}^{-2} \mathrm{~K}^{-1}$ for $10 \mathrm{~cm}$ due to the augmentation of the hydraulic diameter, following Eq. (5). The U-value then reaches a maximum of $1.76 \mathrm{~W} \mathrm{~m}^{-2} \mathrm{~K}^{-1}$ for a thickness of $2.6 \mathrm{~cm}$, corresponding to a good compromise between airflow rate and convective heat transfer coefficients.

In the insulating case, the U-value decreases to reach a minimum value of $0.72 \mathrm{~W} \mathrm{~m}^{-2} \mathrm{~K}^{-1}$ for $3.6 \mathrm{~cm}$, before increasing very slowly again: before this value, there is no convection in the vertical air gaps, and the thermal resistance increases with the thickness. Around $2.8 \mathrm{~cm}$, the convection starts slowly, with for example a Nusselt number in the outer cavity of 1.02 for $2.8 \mathrm{~cm}$. After $3 \mathrm{~cm}$, the convection increases, until a Nusselt number of 3.8 is reached in the outer vertical air gap for $10 \mathrm{~cm}$ thickness.
The ratio between $U$-value in the conducting case and U-value in the insulating case reaches a maximum of 2.4 for a gap thickness of $2.8 \mathrm{~cm}$, with a U-value in the insulating case of $0.72 \mathrm{~W}$ $\mathrm{m}^{-2} \mathrm{~K}^{-1}$, and a U-value in the conducting case of $1.76 \mathrm{~W} \mathrm{~m} \mathrm{~m}^{-2} \mathrm{~K}^{-1}$. However, the validation has shown that the model tends to overestimate the U-value for thin air gaps, so this ratio may be lower in reality, although the overestimating effect is lower for low temperature differences.

Also, for air gaps thicker than $3 \mathrm{~cm}$, the free convection in the vertical air gaps, between the two surrounding surfaces, is no more negligible compared to the forced convection, since the condition $\mathrm{Gr} /(\operatorname{Re})^{2} \ll 1$ is no more verified [22]. For $3 \mathrm{~cm}$, this ratio equals 0.11 , while for a thickness of $10 \mathrm{~cm}$ for example, this ratio equals 1.24. For air gap with larger thicknesses, Computational Fluid Dy- 


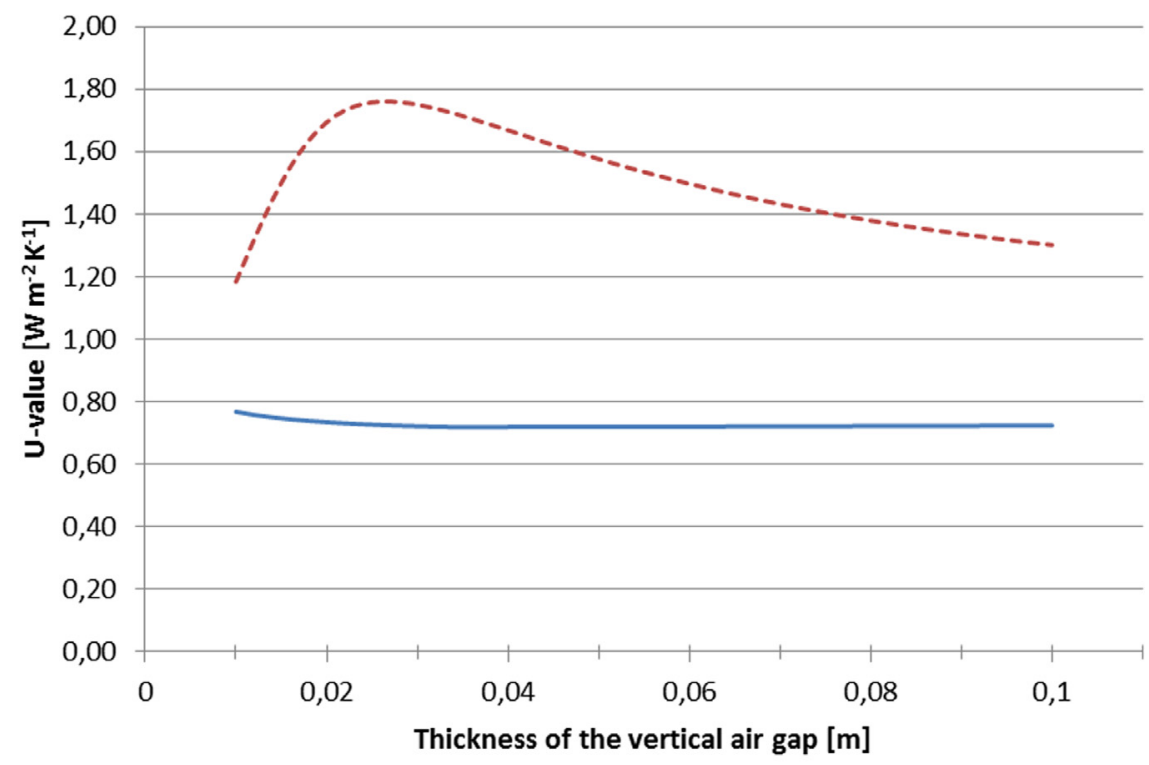

- U-value, insulating state -----U-value, conducting state

Fig. 7. U-value in the insulating and conducting state versus thickness of the vertical air columns, without solar irradiance.

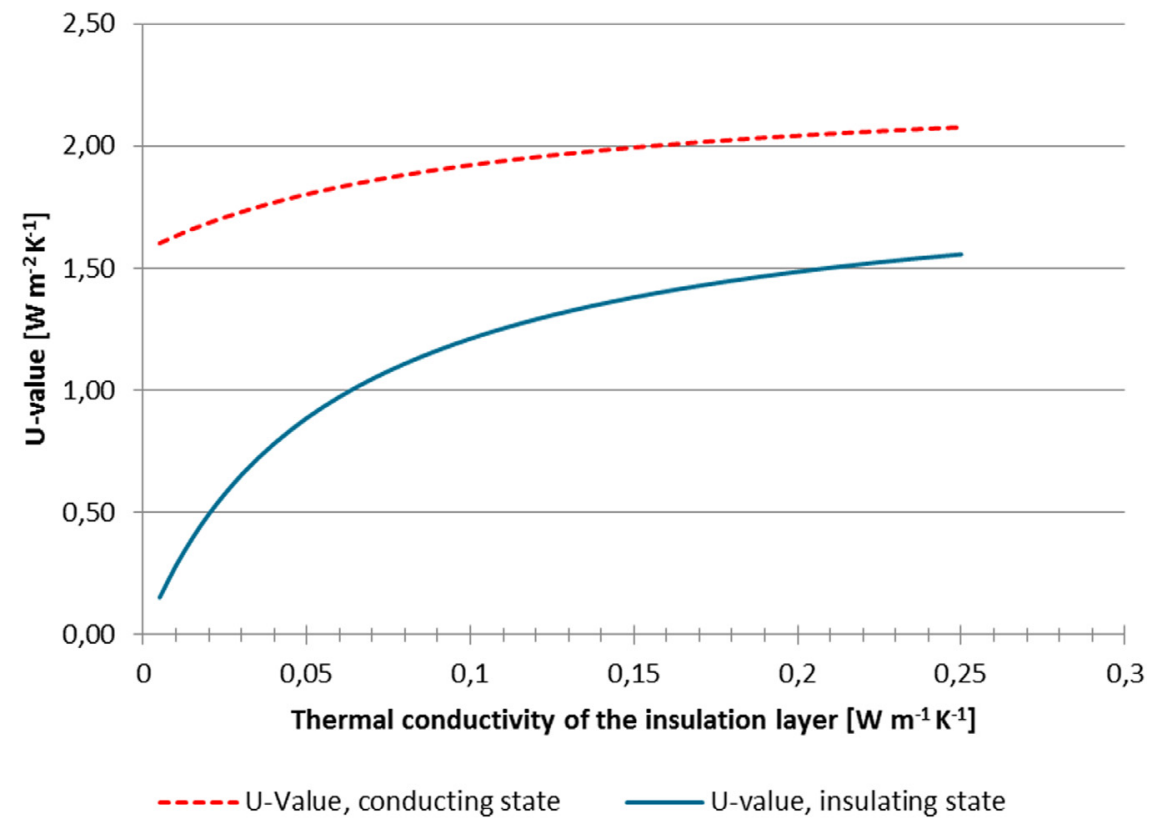

Fig. 8. U-value in the insulating and conducting state versus thermal conductivity of the insulation layer, without solar irradiance.

namics could help to understand the interactions between internal convection between the two surrounding surfaces within each of the vertical air gaps, and large scale convection between the inner and outer vertical air gaps.

The influence of the thickness of the vertical and horizontal air gaps has also been investigated experimentally with measurements $9 \mathrm{C}$ and 10C. Compared to measurements $7 \mathrm{C}$ and $8 \mathrm{C}$, the air gaps were $30 \mathrm{~mm}$ thick instead of $17.5 \mathrm{~mm}$. The insulation thickness was $10 \mathrm{~mm}$. Also here, an increase of the U-value was observed, with U-values of 1.83 and $2.03 \mathrm{~W} \mathrm{~m}^{-2} \mathrm{~K}^{-1}$ for $14 \mathrm{~K}$ and $29 \mathrm{~K}$ temperature differences, respectively, and $30 \mathrm{~mm}$ gaps, instead of 1.72 and $1.86 \mathrm{~W} \mathrm{~m}^{-2} \mathrm{~K}^{-1}$ for $14 \mathrm{~K}$ and $28 \mathrm{~K}$ temperature differences and $17.5 \mathrm{~mm}$ gaps. See also $[15,18]$ for more details on the measurement results.
With solar irradiance, the g-value in the conducting case is almost constant around 0.085 and slightly higher than in the insulating case.

\subsection{Thermal conductivity of the insulation layer}

The thermal conductivity of the insulation layer is varied. The g-value was not calculated for this "virtual" material. The results are visible in Fig. 8.

In the conducting case, the lower the thermal conductivity of the insulation layer, the higher is the airflow rate: since the temperature difference between the outer and inner air column is higher, the difference of density that is the driving force of the convection is higher, with a maximum airflow rate in the outer air 
gap of $5.6 \mathrm{~m}^{3} \mathrm{~h}^{-1}$ for $0.005 \mathrm{~W} \mathrm{~m} \mathrm{~m}^{-1} \mathrm{~K}^{-1}$. This compensates partly the decrease of conduction through the insulation and leads to an $\mathrm{U}$-value of $1.60 \mathrm{~W} \mathrm{~m}^{-2} \mathrm{~K}^{-1}$ for a thermal conductivity of $0.005 \mathrm{~W}$ $\mathrm{m}^{-1} \mathrm{~K}^{-1}$. This thermal conductivity value corresponds for example to vacuum insulation and results in the highest U-value ratio of 10.5 between conducting and insulating states, with an U-value of $0.09 \mathrm{~W} \mathrm{~m}^{-2} \mathrm{~K}^{-1}$ in the insulating state. It seems to be very advantageous to have a very low thermal conductivity for the insulating layer.

\section{Conclusion}

A detailed model of the new translucent facade element with switchable insulation has been presented. The advantage of the introduced nodal model is that it can be easily applied for new geometries and that it can be used in the early phases of a building process, where there is neither the time nor the budget available for detailed CFD simulations. While the model uses strong assumptions for the thermal and hydraulic submodels, there is a good agreement with the U-value measurements presented in different geometrical cases: for the different geometries and switching state investigated, the Root Mean Square Error (RMSE) is $0.183 \mathrm{~W}$ $\mathrm{m}^{-2} \mathrm{~K}^{-1}$ and the mean difference between model and measurement is $9.5 \%$. The model has a lower accuracy for cases with a low hydraulic diameter or a low thermal resistance of the insulation panel. This may be due to the fact that the hypothesis of symmetric heating is then no more valid.

In a second step, the model was used for a parametric analysis. The monitored output variable were the $\mathrm{U}$ - and g-values. Increasing the height does not improve the performance of the element, despite the chimney effect. The thickness of the vertical air gaps is a decisive parameter, with a ratio between U-value in the conducting case and $U$-value in the insulating case reaching a maximum of 2.4 for a gap thickness of $2.8 \mathrm{~cm}$, corresponding to an U-value in the insulating case of $0.72 \mathrm{~W} \mathrm{~m}^{-2} \mathrm{~K}^{-1}$, and a U-value in the conducting case of $1.76 \mathrm{~W} \mathrm{~m} \mathrm{~m}^{-2} \mathrm{~K}^{-1}$. The thickness of the insulation layer has a strong impact on the g-value, but there is no significant difference between the g-value in the insulating and conducting state, mainly due to the low secondary heat gain. Varying the insulation's thermal conductivity produce the highest U-value ratio with an $\mathrm{U}$-value of $0.09 \mathrm{~W} \mathrm{~m}^{-2} \mathrm{~K}^{-1}$ in the insulating state and $1.60 \mathrm{~W} \mathrm{~m}^{-2} \mathrm{~K}^{-1}$ in the conducting state for a thermal conductivity of $0.005 \mathrm{~W} \mathrm{~m}^{-1} \mathrm{~K}^{-1}$. Aerogel material, which can have a thermal conductivity of about $0.013 \mathrm{~m}^{-1} \mathrm{~K}^{-1}$ [34] as well as a visible direct hemispherical transmittance between 0.43 and 0.85 [35] for a $10 \mathrm{~mm}$ thick layer could produce an interesting compromise between U-value ratio and light transmittance, as could vacuum glazing.

Another performant switchable insulation technology is the removable films system creating closed air layers in series and presented in [9-11]. This removable system can be switched from an $\mathrm{U}$-value of about $0.14 \mathrm{~W} \mathrm{~m} \mathrm{~W}^{-2} \mathrm{~K}^{-1}$ in the insulating state to an Uvalue of about $2.7 \mathrm{~W} \mathrm{~m} \mathrm{~m}^{-2} \mathrm{~K}^{-1}$ in the conducting state, for an element thickness of $20 \mathrm{~cm}$. Using for example a vacuum insulation panel as insulation pane, the closed element presented in this contribution could reach a lower U-value in the insulating state for a lower overall thickness, but the U-value in the conducting state would also be much lower, which would reduce the building's summer night cooling potential. The low overall thickness of the element presented in the current contribution compared to the removable system may be an important factor for building planners.

The next step would be to use the model for a multicriteria optimization, in order to maximize the U-value switching range. Also, Computational Fluid Dynamic simulations could be used to validate more accurately the hydraulic part of the system as well as to calculate the cases that beyond the limit of the model, such as a different hydraulic diameter for the vertical and horizontal air gaps. To ameliorate the accuracy of the model, CFD could also be used to calculate different convective heat transfer coefficients on each boundaries of the air columns in the conducting case.

\section{Acknowledgements}

This work was funded by the BMWi (Germany ministry of economic affairs) under the auspices of grant 03ET1032B (Integriertes Wärmemanagement-Fassadenelement (WaMaFat)) which is part of the EnOB (Forschung fr Energieoptimiertes Bauen) initiative.

The author also acknowledges the financial contribution of the Arconic foundation to the writing of this paper.

\section{References}

[1] T. Berger, C. Amann, H. Formayer, A. Korjenic, B. Pospichal, C. Neururer, R. Smutny, Impacts of external insulation and reduced internal heat loads upon energy demand of offices in the context of climate change in vienna, austria, J. Build. Eng. 5 (2016) 86-95, doi:10.1016/j.jobe.2015.11.005.

[2] T.E. Kuhn, Solar control: a general evaluation method for facades with venetian blinds or other solar control systems, Energy Build. 38 (6) (2006) 648-660, doi:10.1016/j.enbuild.2005.10.002.

[3] H.R. Wilson, Solar control coatings for windows, in: K. Grassie, E. Teuckhoff, G. Wegner, J. Hausselt, H. Hanselka (Eds.), Functional Materials, 13, 2006.

[4] T. Kuhn, K. Fath, C. Bales, R. Nouvel, R. Fedrizzi, Project INSPIRE, deliverable 2.3 RES availability survey and boundary conditions for simulations, 2014.

[5] M.S. Sodha, J.K. Nayak, N.K. Bansal, I.C. Goyal, Thermal performance of a solarium with removable insulation, Build. Environ. 17 (1) (1982) 23-32, doi:10 1016/0360-1323(82)90006-3

[6] R. Leppkes, H. Olbrich, Polystyrol-Schaumstoffkugeln für die variable Wärmedämmung und Beschattung von transparenten Gebäudeteilen, 1987Patent DE 000003730023C2.

[7] F. Stazi, A. Vegliò, C. Di Perna, P. Munafò, Retrofitting using a dynamic envelope to ensure thermal comfort, energy savings and low environmental impact in mediterranean climates, Energy Build. 54 (2012) 350-362, doi:10.1016/ j.enbuild.2012.07.020.

[8] M. Kimber, W.W. Clark, L. Schaefer, Conceptual analysis and design of a partitioned multifunctional smart insulation, Appl. Energy 114 (2014) 310-319, doi:10.1016/j.apenergy.2013.09.067.

[9] T. Pflug, B. Bueno, M. Siroux, T.E. Kuhn, Potential analysis of a new removable insulation system, Energy Build. 154 (2017) 391-403, doi:10.1016/j.enbuild. 2017.08.033.

[10] S. Kvasnin, lsolationsvorrichtung für Fenster, 2013. Patent DE 102013001176A1.

[11] S. Kvasnin, Isolationsvorrichtung für Fenster oder Fassaden, 2014, Patent DE 202014000533 U1.

[12] R. Caps, J. Hetfleisch, J. Fricke, Vakuumwärmedämmpanel, 1996, Patent DE 196 47567 C 2.

[13] C.-E. Hagentoft, Enhanced U-value of a wall structure using interior sensor driven forced or natural convection, in: Proceedings of the 2nd Central European Symposium on Building Physics, Vienna, Austria, 2013, pp. 805-810.

[14] A. Berge, C.-E. Hagentoft, P. Wahlgren, B. Adl-Zarrabi, Effect from a variable UValue in adaptive building components with controlled internal air pressure, Energy Proced. 78 (2015) 376-381, doi:10.1016/j.egypro.2015.11.677.

[15] T. Pflug, T.E. Kuhn, R. Nörenberg, A. Glück, N. Nestle, C. Maurer, Closed translucent façade elements with switchable U-value-A novel option for energy management via the facade, Energy Build. 86 (2015) 66-73, doi:10.1016/j.enbuild. 2014.09.082.

[16] N. Nestle, T. Pflug, A. Daiss, K. Hahn, T. Kuhn, C. Maurer, J. Wienold, A. Glück, R. Nörenberg, J.M. Szeifert, E. Khazova, A. Löffler, Construction element having a controllable heat-transfer coefficient U, 2015, Patent US 20150361654 A1.

[17] BASF, Marketinginformation: Basotect® - der vielseitige Schaumstoff aus Melaminharz, 2014, Www.basotect.de.

[18] T. Pflug, Development, characterization and Evaluation of switchable facade elements, Université de Strasbourg, Laboratoire ICube., 2016 Ph.D. thesis.

[19] Verein Deutscher Ingenieure, Heat Atlas, VDI-buch, 2nd ed., Springer, Berlin and New York, 2010.

[20] DIN 673:2011-04, Glass in building -Determination of thermal transmittance (U-value) - Calculation method; German version, DIN Deutsches Institut für Normung.

[21] ISO 15099:2003, Thermal performance of windows, doors and shading devices - Detailed calculations, Technical Committee ISO/TC 163.

[22] A. Bejan, Convection Heat Transfer, Fourth Ed., John Wiley \& Sons, Inc, 2013.

[23] J.L. Wright, Correlation to quantify convective heat transfer between vertical window glazings, ASHRAE Trans. 102 (1) (1996).

[24] J.A. Duffie, W.A. Beckman, Solar Engineering of Thermal Processes, Third Ed., John Wiley \& Sons, Inc, 2006.

[25] Lawrence Berkeley National Laboratory, WINDOW 7.2, 2015, https://windows. lbl.gov/software/window/window.html.

[26] EN 410:2011, Glass in building - Determination of luminous and solar characteristics of glazing, European Committee for Standardization. 
[27] T.E. Kuhn, Design, development and testing of innovative solar-control facade systems, National and Kapodistrian University of Athens, 2016 Ph.D. thesis.

[28] ISO 8302:1991, Thermal insulation - Determination of steady-state thermal resistance and related properties - Guarded hot plate apparatus, Technical Committee ISO/TC 163.

[29] F. Gloriant, P. Tittelein, A. Joulin, S. Lassue, Modeling a triple-glazed supply-air window, Build. Environ. 84 (2015) 1-9, doi:10.1016/j.buildenv.2014.10.017.

[30] R.K. Shah, A.L. London, Laminar flow forced convection in ducts: a source book for compact heat exchanger analytical data, Advances in heat transfer. Supplement, 1, Academic Press, New York, 1978.

[31] D.A. Nield, Forced convection in a parallel plate channel with asymmetric heating, Int. J. Heat Mass Transf. 47 (25) (2004) 5609-5612, doi:10.1016/j. ijheatmasstransfer.2004.07.006.
[32] D.A. Nield, Erratum to: "forced convection in a parallel plates channel with asymmetric heating" [Int. J. Heat Mass Transfer 47 (2004) 5609-5612], International Journal of Heat and Mass Transfer 51 (7-8) (2008) 2108, doi:10.1016/ j.ijheatmasstransfer.2007.09.044.

[33] A. Schwab, Zur wärmeübertragung bei mischkonvektion in luftdurchströmten bauteilen, Bauphysik 24 (6) (2002).

[34] E. Cuce, P.M. Cuce, C.J. Wood, S.B. Riffat, Toward aerogel based thermal superinsulation in buildings: a comprehensive review, Renew. Sustain. Energy Rev. 34 (2014) 273-299, doi:10.1016/j.rser.2014.03.017.

[35] M. Reim, G. Reichenauer, W. Körner, J. Manara, M. Arduini-Schuster, S. Korder, A. Beck, J. Fricke, Silica-aerogel granulate - structural, optical and thermal properties, J. Non-Cryst. Solids 350 (2004) 358-363, doi:10.1016/j.jnoncrysol. 2004.06.048. 